\title{
Percepção das pessoas trans acerca do acesso ao mercado de trabalho
}

\section{Transgender people's perception of access to the labor market}

\author{
Percepción de las personas trans \\ sobre el acceso al mercado laboral
}

\section{Fabrício Fonseca Ferreira' ${ }^{1}$ (1) Thaís Monielly Sousa Ribeiro ${ }^{2}$ (1) Worney Ferreira de Brito $^{3}$ (1)}

1Autor para correspondência. Faculdade de Saúde e Humanidades Ibituruna (Montes Claros). Minas Gerais, Brasil. fabriciofonsecaferreira@gmail.com ${ }^{2-3}$ Faculdade de Saúde e Humanidades Ibituruna (Montes Claros). Minas Gerais, Brasil. thaismonielly2@gmail.com, worney.brito@fasi.edu.br

RESUMO I INTRODUÇãO: A transexualidade define-se como a não identificação com o gênero socialmente atribuído no nascimento. Diante do exposto, travestis e transexuais são pessoas que ultrapassam as fronteiras do gênero e produzem uma desestruturação binária e polarizada de gênero que contesta o modo de vida heterossexual e cisgênero, assim refletindo diretamente em vários aspectos de suas vidas, principalmente no que tange ao acesso ao mercado de trabalho formal. OBJETIVO: Explorar a percepção de pessoas transexuais acerca das dificuldades de acesso ao mercado de trabalho formal. MATERIAIS E MÉTODOS: A pesquisa foi realizada com pessoas transgênero, das cidades do norte de Minas Gerais (MG) e que tenham tido experiência no mercado de trabalho. O material empírico foi produzido a partir de entrevistas com as/os participantes através do critério de saturação e aplicação do questionário WHOQOL-Bref, tendo os dados sido interpretados com base na análise do discurso de Pêcheux. RESULTADOS E DISCUSSÃO: Observou-se que a percepção das pessoas trans acerca do acesso ao mercado de trabalho é fortemente influenciada pelos papéis de gênero com que se identificam, atrelada a uma dificuldade de acesso ao ensino, com reflexos na qualidade de vida dessas pessoas, oriundos de atitudes de preconceito. CONSIDERAÇõES FINAIS: A transgeneridade é um tema importante que abarca as questões de gênero e de sexualidade. O desenvolvimento de pesquisas científicas voltadas para a população LGBTQIA+ se faz mais que necessário, uma vez que a sociedade cis e heteronormativa sistematicamente precariza e invisibiliza essas vivências.

PALAVRAS-CHAVE: Pessoas Transgênero. Percepção. Mercado de trabalho. Qualidade de vida.

ABSTRACT | INTRODUCTION: Transsexuality is defined as non-identification with the socially assigned gender at birth. Given the above, transvestites and transsexuals are people who go beyond gender boundaries and produce a binary and polarized breakdown of gender that challenges the heterosexual and cisgender way of life, thus directly reflecting on various aspects of their lives, especially with regard to access to the formal labor market. OBJECTIVE: To explore the perception of transgender people about the difficulties in accessing the formal job market. MATERIALS AND METHODS: A survey was conducted with people who identify themselves as transgender, from cities in the north of Minas Gerais (MG), and who had had experience in the labor market. The empirical material was produced from the interviews with the participants, by means of the saturation criterion and the use of the WHOQOL-Bref questionnaire; all data were interpreted based on Pêcheux's discourse analysis. RESULTS AND DISCUSSION: It was observed that the perception of trans people about their access to the job market is influenced by the gender roles with which they identify, linked to a difficulty in accessing education, with reflections on the quality of life of these people, originated from attitudes of prejudice. CLOSING REMARKS: Transgenderism is an important issue which encompasses gender and sexuality issues. The development of scientific research aimed at LGBTQIA+ population is more than necessary, since the cis and heteronormative society systematically undermines and makes these experiences invisible.

KEYWORDS: Transgender People. Perception. Job Market. Quality of Life. 
RESUMEN | INTRODUCCIÓN: La transexualidad se define como la no identificación con el género socialmente asignado al nacer. Dado lo anterior, los travestis y transexuales son personas que van más allá de las fronteras de género y producen una ruptura binaria y polarizada de género que desafía la forma de vida heterosexual y cisgénero, reflejando así directamente diversos aspectos de su vida, especialmente en lo que respecta al acceso a la mercado laboral formal. OBJETIVO: Explorar la percepción de las personas trans sobre las dificultades para acceder al mercado laboral formal. MATERIALES Y MÉTODOS: La encuesta se realizó con personas que se identificaron como transgénero, de ciudades del norte de Minas Gerais y que han tenido experiencia en el mercado laboral. El material empírico fue elaborado a partir de entrevistas con los participantes a través del criterio de saturación, aplicación del cuestionario WHOQOL-Bref y los datos fueron interpretados con base en el análisis del discurso de Pêcheux. RESULTADOS Y DISCUSIÓN: Se observó que la percepción de las personas trans sobre el acceso al mercado laboral está fuertemente influenciada por los roles de género que desempeñan, ligado a una dificultad para acceder a la educación con reflexiones sobre la calidad de vida de estas personas, derivadas de actitudes de prejuicio. CONSIDERACIONES FINALES: La transgeneridad es un tema importante que engloba cuestiones de género y sexualidad y el desarrollo de investigaciones científicas dirigidas a la población LGBTQIA+ es más que necesario, ya que la sociedad cis y heteronormativa precariza e invisibiliza sistemáticamente estas experiencias.

PALABRAS CLAVE: Personas transgénero. Percepción. Mercado de trabajo. Calidad de vida.

\section{Introdução}

As produções com relação aos estudos de gênero tiveram seu início nos anos 1960, através de movimentos sociais e luta das mulheres quanto ao papel secundário que desempenhavam em relação aos homens. Em meados de 1970 e 1980, o campo de estudos de gênero ou relações de gênero chegou ao Brasil em torno da condição feminina (Silva et al., 2015).

Para Butler (2003), o gênero é socialmente construído, aprendido e performado. A autora argumenta que o sujeito deve ter a liberdade de reinventar seu gênero como melhor convém, sem a necessidade de se adequar às normas e condutas que não foram escolhidas por ele. Pontua ainda a importância de não pensar em gênero como extensão do sexo biológico, mutualista a uma lógica binária, feminino e masculino, mas admitir as diversas expressões e desdobramentos possíveis em relação à identidade humana (Cruz et al., 2020).

É necessário elucidar alguns termos para melhor compreensão em torno dos aspectos que envolvem gênero e sexualidade, tais como: identidade de gênero, expressão de gênero, papel de gênero e orientação sexual. A identidade de gênero é o gênero com o qual uma pessoa se identifica, que pode ou não concordar com o gênero que Ihe foi atribuído no nascimento, ou seja, uma pessoa pode nascer com um sexo biológico - homem ou mulher - e se identificar com o gênero oposto - masculino ou feminino -, por exemplo (Jesus, 2012).

Jesus (2012) define a expressão de gênero como a forma com que a pessoa se apresenta, sua aparência e seu comportamento, de acordo com as expectativas sociais de um determinado gênero culturalmente construído. $O$ papel de gênero é o modo de agir em determinadas situações conforme o gênero atribuído desde o nascimento, de cunho social e não biológico. A orientação sexual é a atração afetivo-sexual por alguém, relativa à sexualidade, sendo ela heterossexual, homossexual, bissexual, pansexual, entre outras.

Quando partem para uma busca pelo corpo desejado ou quando não se sentem pertencentes ao seu sexo biológico e ao gênero que lhes foi atribuído, surge nos sujeitos um sentimento de insatisfação que é acompanhado por uma necessidade de atender e se adequar aos padrões sociais que reforçam os comportamentos estereotipados da conduta que homens e mulheres devem exercer. Ao estabelecer e idealizar atitudes tidas como modelos de masculinidade e feminilidade, pode-se gerar um sofrimento psíquico para algumas pessoas (Cruz et al., 2020).

A transexualidade define-se como a não identificação com o gênero socialmente atribuído no nascimento. No Brasil, há quem considere as/os transgêneros como uma categoria à parte das pessoas travestis e transexuais. Há ainda aquelas pessoas que não se identificam com qualquer gênero. Não existe consenso quanto à denominação, é comum que se utilize o termo "queer", a antiga denominação "andrógino" ou mesmo a palavra transgênero, que é a adotada neste estudo. Para Jesus (2012, p. 16), a categoria de identificação transgênero prescinde de uma alteração corporal cirúrgica, tal qual sintetiza: "Em suma, ao contrário do que se costuma pensar, o que determina a identidade de gênero transexual é a forma como as pessoas se identificam, e não um procedimento cirúrgico." 
Reis (2019) infere que a visão sobre identidades segue a época e os mecanismos em que as pessoas se encontram, em forma de ações e discursos que definem todo o processo a respeito da subjetividade, ou seja, os conceitos de identificação vão ser alterados com as mudanças de representações sociais e os conceitos empregados com a mudança dos tempos.

Ante o exposto, é comum se observar que, na sociedade regida por conceitos heterocêntricos, são adotadas atitudes de preconceito frente à simples presença de travestis e transexuais e, na maioria das vezes, as discriminações se iniciam no contexto do ambiente familiar e da comunidade em que estão inseridas/os, refletindo diretamente no acesso ao mercado de trabalho formal. A trajetória para a inserção e ascensão em uma carreira exige capacitação, entretanto, as travestis, transexuais e transgêneros enfrentam obstáculos específicos nesta trajetória (Kaffer et al., 2016).

As pessoas transexuais são marginalizadas e recebem quase que nulas oportunidades na sociedade, sendo notadamente rara a inserção no mercado de trabalho. Para Kaffer et al. (2016, p. 2), a falta de oportunidades nesse âmbito pode ser explicada pelo fato de que pessoas travestis e transexuais desafiam as normas de gênero: "é importante destacar que travestis e transexuais são pessoas que abancam as fronteiras do gênero, causam insegurança na estruturação binária e polarizada de gênero que contestam o modo de vida hétero, via de regra, considerado normal pela socieda$d e^{\prime \prime}$. Essa "fuga do normal" não costuma ser bem-vista pela sociedade e diversas vezes representa perigo para essas pessoas.

A mortalidade de pessoas LGBTQIA+ ${ }^{1}$ é um indicador revelador da estigmatização sofrida por essa população. Sousa e Arcoverde (2019) constatam que apenas no primeiro semestre de 2019, por exemplo, o Brasil registrou mais de 130 mortes de pessoas LGBTQIA+ por questão de preconceito. Viver sob a perspectiva de se tornar estatística cria estereótipos extremamente difíceis de se derrubar, o que inclui a não valorização dessas vidas.

Segundo o Manual de Comunicação LGBT (elaborado pela Associação Brasileira de Lésbicas, Gays, Bissexuais, Travestis e Transexuais/ABGLT²), a expressão "sair do armário" (momento em que a pessoa se abre sobre sua sexualidade e identidade de gênero) é demasiadamente especial para a comunidade LGBTQIA+ e tem grande significado pessoal e social. O movimento defende que cada pessoa tem o seu momento, e oferece apoio e orientação, quando assim solicitado. Assumirse está para além de um ato individual, diz respeito a uma prática política: "O ato de assumir-se é extremamente significativo, pois traz implicações também ao próprio movimento" (Associação Brasileira de Lésbicas, Gays, Bissexuais, Travestis e Transexuais, 2010, p. 19).

Travestis e transexuais possuem competência e capacidade quanto qualquer outra pessoa, mas, por consequência do preconceito e da discriminação, torna-se inviável a inserção destas pessoas no mercado de trabalho. Ao assumirem suas identidades de gênero perante a sociedade, geram intolerância e, assim, o ponto crucial é demonstrar que respeitar as diferenças humanas gera integração entre as pessoas, bem como um crescimento em todos os setores da sociedade. Para isso, é necessário evitar o julgamento de pessoas apenas pelas características físicas exteriores, a repressão de seus direitos e deixar que isso sirva como uma barreira para sua contratação profissional (Maria, 2020).

Maria (2020) argumenta que restringir categorias profissionais como supostamente apropriadas às travestis e transexuais provoca um sentimento de marginalização nessa população, deixando de inseri-las na sociedade e gerando uma crença coletiva de que não se deve ter obrigação com essas pessoas. Assim, o que define o local onde podem trabalhar não parte da vontade das travestis e das transexuais, mas dos padrões dominantes, ficando restritas a áreas de atuação profissional em que elas são menos rejeitadas pela sociedade.

\footnotetext{
${ }^{1}$ LGBTQIA+ é o movimento social e político que defende a representatividade e a busca por direitos para essa comunidade. O seu nome demonstra a sua luta por mais igualdade e respeito às variadas formas de diversidade sexual: L= Lésbicas; $G=\mathrm{Gays}$; $\mathrm{B}=$ Bissexuais; $\mathrm{T}=\mathrm{Transexuais;} \mathrm{Q}=\mathrm{Queer}$ I= Intersexo; $\mathrm{A}=\mathrm{Assexual}$ e o "+" sugere a inclusão de outros grupos de variedade sexual existentes (Silva, 2020).

${ }^{2}$ O Manual de Comunicação LGBT da Associação Brasileira de Lésbicas, Gays, Bissexuais, Travestis e Transexuais (ABGLT) é resultado do trabalho colaborativo de militantes, jornalistas e outros profissionais ligados, de alguma maneira, ao segmento LGBT no Brasil.
} 
O Artigo XXIII da Declaração Universal dos Direitos Humanos, promulgada pela Organização das Nações Unidas em 1948, afirma que: "Toda pessoa tem direito ao trabalho, à livre escolha de emprego, a condições justas e favoráveis de trabalho e à proteção contra o desemprego". Portanto, diante da negativa de possibilidade ao que se apresenta nesta Declaração, este trabalho visa levantar uma discussão acerca das concepções dos fatores que contribuem para a discriminação ao público transexual, quando se trata de exercer a liberdade de seus direitos e deveres com foco no exercício de uma profissão.

O objetivo da pesquisa foi o de explorar a percepção de pessoas transexuais acerca dos percalços observados por esses sujeitos durante o processo de inserção no mercado de trabalho, das influências dos papéis de gênero e expressão de gênero ao assumirem suas identidades e de como percebem e avaliam o conceito de qualidade de vida em contraste com o preconceito em suas vidas.

\section{Método}

Trata-se de uma pesquisa qualitativa, de caráter exploratório, realizada na região Norte do Estado de Minas Gerais, no município de Montes Claros, de médio porte, um dos mais importantes em decorrência do processo de urbanização atrelado ao seu papel de cidade polo regional. O resultado dessa expansão foi a periferização, assentamentos subnormais, formação de bairros de baixa densidade demográfica e um grande número de vazios urbanos. Até a década de 1970, a base econômica de Montes Claros era a agropecuária e as atividades mercantis, entretanto, essa situação se modificou após a criação da Superintendência de Desenvolvimento do Nordeste (SUDENE), desenvolvida pelo Governo Federal, no intuito de fomentar o processo de industrialização da região Nordeste do país (Gomes, 2007).

A população da pesquisa foi constituída de pessoas que se identificam como transgêneros ou transexuais, em idade de trabalho, residentes da região Norte do estado de Minas Gerais. Foram entrevistadas seis pessoas, número definido por conveniência na busca de pessoas que se encaixassem aos critérios; houve contato com oito participantes, mas dois não se dispuseram a participar, um por questão de contato direto com os pesquisadores e o outro por dificuldade de contato pela internet. Os critérios de inclusão para a pesquisa correspondiam a serem maiores de 18 anos e se identificarem como pessoas transgêneros e, em contrapartida, os critérios de exclusão foram baseados nos indivíduos que nunca tiveram experiência na busca por trabalho, vivência laboral ou situações de cunho trabalhista.

Os participantes correspondem a três homens trans (FtoM) e três mulheres trans (MtoF), sendo que três delas/es têm curso superior completo e três, o ensino médio completo. Duas participantes são negras, um considera-se pardo e três são pessoas brancas. A pesquisa foi coletada entre fevereiro e junho de 2021 e as/os participantes têm idades entre 19 e 30 anos.

Os instrumentos metodológicos foram um roteiro de entrevista pré-estabelecido para elegibilidade à pesquisa, um miniquestionário para caracterização demográfica e questões semiestruturadas relativas a suas vivências no mercado de trabalho e a relação dos gêneros dos participantes com esse âmbito da sociedade.

O instrumental também contou com o questionário do World Health Organization Quality of Life em sua versão Bref (abreviada), também conhecida como WHOQOL-Bref, que corresponde a um instrumento desenvolvido pela Organização Mundial da Saúde (OMS), com o intuito de avaliar a qualidade de vida dos indivíduos. O questionário dispõe de 26 questões cujas respostas seguem uma escala Likert (de 1 a 5 , quanto maior a pontuação, melhor a qualidade de vida). As perguntas 1 e 2 versam sobre a qualidade de vida geral; as outras 24 facetas compõem 4 domínios que são: físico, psicológico, relações sociais e meio ambiente (Fleck, 2000).

Para a escolha das/os participantes, no primeiro momento, foram identificadas pessoas que se encaixassem nos critérios e objetivos da pesquisa por meio da busca ativa. Em seguida, através da técnica de Bola de neve (Snowball), em que um/a participante indica outras/os, de forma espontânea. Posteriormente, todas/os preencheram o formulário online em que constava o Termo de Consentimento Livre e Esclarecido (TCLE), responderam ao WHOQOL-Bref e à entrevista. 
Por razões do regime de distanciamento social recomendado pela Organização Mundial de Saúde (OMS) e seguido pelo Brasil em decorrência da pandemia da covid-19, os instrumentos e procedimentos foram adaptados para respeitar as recomendações. Este material inclui o Termo de Consentimento Livre e Esclarecido para participação em pesquisa (TCLE) e a testagem do WHOQOL-Bref nos modelos online e presencial, bem como as entrevistas com as/os participantes, que foram realizadas por meio dos aplicativos WhatsApp (pelo método de gravação de mensagem de áudio) ou pela plataforma Google Meet, o que ficou a critério das/os participantes da pesquisa, que fizeram essa escolha durante o contato para a sua participação.

A coleta de dados online demanda adaptações, entretanto, produz possibilidades de pesquisas importantes, quando se caracterizam por previamente facilitarem o estabelecimento do rapport com os participantes, promovendo-lhes o senso de conforto e segurança para a realização da entrevista. Isto se deve ao fato de que os sujeitos podem se mostrar mais à vontade em participar de um estudo por estar em sua própria casa ou se sentir mais confortáveis para desistir da entrevista online, se assim desejarem, em comparação à entrevista presencial, o que muitas vezes é feito ao se desconectar o dispositivo (Schmidt et al., 2020).

Após a transcrição das entrevistas e da sua leitura repetida e aprofundada, discutiu-se acerca das impressões sobre a pesquisa, a fim de se realizar a análise do discurso baseada em Pêcheux, para observação e categorização dos dados das entrevistas e análise das respostas da aplicação do WHOQOL-Bref. Segundo Caregnato e Mutti (2006), a análise do discurso de Michel Pêcheux é um estudo sobre discurso em que se estabelece uma ligação entre as relações existentes no discurso com a língua e a história ou a língua e a ideologia.

O presente artigo, por ser fruto de uma pesquisa que envolve seres humanos, foi aprovado pelo Comitê de Ética das Faculdades Integradas do Norte de Minas - FUNORTE, conforme a Resolução do Conselho Nacional de Saúde (CNS) $n^{\circ} 466$ de 12 de dezembro de 2012, sob o parecer $n^{\circ} 4.583 .502$.

\section{Resultados e discussão}

Os dados coletados foram sintetizados e categorizados da seguinte maneira: 1) O reflexo das concepções de normatividade sobre os processos de autoaceitação das pessoas transexuais; 2) Educação e empregabilidade para a população trans; e 3) A influência dos papéis de gênero na busca pela qualidade de vida da população trans, conforme pode-se ler em seguida.

\section{0 reflexo das concepções de normatividade sobre os processos de autoaceitação das pessoas transexuais}

Essa categoria tem como foco discutir e analisar a percepção dos/as participantes acerca do caráter de identificação social, o desejo de respeito pela forma como expõem seus gêneros e a exposição dos seus corpos, na forma como expressam suas construções pessoais - a chamada expressão de gênero -, mesclando as falas durante a entrevista e o questionário WHOQOL-Bref. As/Os participantes expressam a importância de serem elas/es mesmas/os, de como se identificam e da relação que têm com o seu corpo, tratando de como se veem e de como são vistas/os por outras pessoas.

Com efeito dos dados empíricos obtidos para compor essa categoria, destaca-se a fala do Participante 1 sobre o momento de se buscar emprego e se expor a um processo seletivo, por exemplo. Ao ser questionado a respeito do que gostaria de falar sobre o tema transexualidade e mercado de trabalho, apresentou a seguinte explanação:

"Eu acho que deveria ser mais, mais sensato, a pessoa virar e perguntar pro outro 'ah, como você gosta de ser tratado?"'. (Participante 1)

A mesma questão pode ser vista na resposta deste referido participante ao WHOQOL-Bref no quesito relativo à aceitação da própria aparência, em que ele responde que não se sente capaz de aceitar sua imagem atual. $O$ dado pode ser interpretado como uma internalização das discriminações ao não respeitarem sua identidade de gênero em determinados contextos. 
Segundo Pedra et al. (2018), o trabalho tem em sociedade uma função de inserção, causando sentimento de pertencimento e dignidade ao dar um propósito, reforçando sua identidade social. Assim, dentre as/os participantes da pesquisa, no que se refere às questões das demandas voltadas para o processo de aceitação das identidades sexuais e da própria normatividade, o Participante 1, na fala em destaque, revelou uma falha do propósito do trabalho neste quesito, quando se trata de pessoas trans.

Concomitante aos objetivos propostos para esta categoria, o discurso a respeito da relação entre a condição de ser transexual e o mercado de trabalho é reforçado pela fala do Participante 4, que diz:

"Então foi complicado nesse início, e eu acredito que tenha sido complicado pra eu achar emprego na época, não só pela falta de experiência... É... mas por questão da aparência mesmo. O que ainda era... Eu tinha uma aparência meio andrógina, e eu acho que isso pegava um pouco na hora de conseguir emprego, né? E em relação a psicologia, é... eu acredito que exercer a minha profissão demorou um pouco mais, porque eu não queria começar a atender sem ter a aparência, né?" (Participante 4)

Ao responder à mesma questão em torno da aceitação da sua própria aparência, o Participante 4 refere como "Médio", ou seja, que ele sente certa aceitação de sua autoimagem, mas não tanto quanto esperava que pudesse sentir. Tal fato é avaliável no mesmo quesito do não respeito ao tratamento que as outras pessoas têm com ele, mas com um impacto menos "prejudicial" pela questão da passabilidade ${ }^{3}$, porém, ainda assim, sendo visto como algo problemático com relação à aparência.

Nota-se, portanto, que o Participante 4 acredita que a questão de sua aparência foi um fator que se mostrou enquanto uma dificuldade para exercer sua atual profissão (psicólogo), pois percebia que precisava parecer fisicamente com uma pessoa cisgênero com que ele se identifica, ou seja, apresentar maior "passabilidade".
Em uma análise sobre a inserção de pessoas transexuais no mercado de trabalho, Adelman et al. (2003) ressaltam que até mesmo os anúncios de emprego já deixam claro que o mercado abre espaço a uma divisão sobre o que homens e mulheres devem fazer. As pessoas que não se encaixam nesses padrões, da forma como a sociedade espera, podem ter um sentimento de rejeição, afetando o seu desempenho naquela função específica, principalmente quando se observa que muitas áreas de trabalho são relacionadas à apresentação da imagem, questão diretamente ligada à expressão de uma identidade de gênero.

Em relação ao exposto, sobre se encaixar em padrões e se sentir bem, a Participante 2 apresentou algo semelhante no WHOQOL-Bref, sobre a aceitação de sua própria aparência como "Nada", ou seja, que não se sente capaz de aceitar sua autoimagem até o momento de preenchimento do questionário e em sua entrevista:

"[...] só que eu amo ser quem eu sou. Eu vivia num corpo que não era meu. Era presa. Eu era uma pessoa tímida, não era comunicativa! A partir do momento que eu falei 'eu não sou isso', que comecei a transição."

(Participante 2).

Tal percepção permite se levar em conta que, mesmo não se sentindo satisfeita com sua própria aparência, a busca para ser e se expressar como deseja produz na respondente certa satisfação. Em contrapartida, sobre a questão do olhar do outro, a Participante 6, ao responder a mesma questão do questionário sobre autoaceitação da aparência, marcou a opção "Muito", o que pode representar, em livre interpretação, uma grande aceitação da sua autoimagem. Ela afirma:

"[...] penso que nossa maior preocupação é o que de fato as pessoas vão pensar da gente e como elas vão julgar nossas ações." (Participante 6).

Assim sendo, é de importante avaliação que, para algumas pessoas trans (mesmo que haja a preocupação sobre as opiniões alheias), há também uma completa satisfação com a autoimagem.

${ }^{3}$ A passabilidade é entendida como o quanto uma pessoa trans aparenta ser uma pessoa cis do gênero com o qual ela se identifica (Carpilovsky, 2020). 
AParticipante 5, querespondeu com "Completamente" à mesma questão do questionário, ou seja, que não sente qualquer insatisfação com sua aparência, ressalta a maneira como a sociedade no geral coloca as concepções que alguns indivíduos depositam sobre as pessoas trans:

"[...] existe uma relação, mas a realidade da grande maioria não é ter passabilidade... Então, quando cê

é uma pessoa trans, assim, que todo mundo olha pra você e todo mundo sabe que você é trans, isso influencia bastante. As pessoas têm preconceito, eles acham que você não é capaz, ou te cobram além do que é necessário!" (Participante 5).

Ao longo da história da sexualidade, enquanto dispositivo histórico, é preciso compreender de que maneira o sujeito moderno se utiliza dessa experiência, em como ela ganha significação, compõe discursos reguladores, normatizadores e como produz verdades, dado aos variados momentos históricos que definem as identidades sexuais e de gênero (Foucault, 1984).

Portanto, a relação entre se perceber enquanto sujeito que se aproxima de uma pessoa cisgênero com que ele se identifica e a maneira que as outras pessoas também irão percebê-lo faz parte de um processo de acepção das normas socialmente construídas, apreendidas e amplamente disseminadas. Assim, as/ os participantes demonstram e reforçam que, ao entenderem seus gêneros e decidirem expressá-los, esperam que sejam respeitadas/os, que essa parte tão importante de suas vidas seja levada em conta nos espaços em que estão inseridas/os e pelas pessoas com as quais interagem.

A sociedade teve grandes avanços que moldaram o século XXI, mas ainda com todas essas mudanças a transfobia é um fato; as pessoas que reforçam esse preconceito, em inúmeras vezes com ataques violentos, fazem-no por não respeitarem ou aceitarem pessoas transexuais, de maneira preconceituosa, independentemente do contato que venham a ter com estas pessoas (Cayres et al., 2020).

Percebe-se nessas respostas um caráter de identificação social, o desejo de respeito pela forma como expõem seus gêneros e seus corpos, na forma como expressam suas construções pessoais: a chamada expressão de gênero. As/Os participantes expressam a importância de serem elas/es mesmas/os, de como se identificam e da relação que têm com o seu corpo, tratando de como se veem e de como são vistas/os por outras pessoas.

As/os participantes demonstram e reforçam que, ao entenderem seus gêneros e decidirem expressá-los, esperam que sejam respeitadas/os, que essa parte tão importante de suas vidas seja levada em conta nos espaços em que estão inseridas/os e pelas pessoas com as quais interagem.

\section{Educação e empregabilidade para a população trans}

Nesta categoria, buscou-se analisar a percepção das pessoas trans com relação ao papel da educação diante do acesso ao mercado de trabalho formal. Sobre a questão da busca pelo emprego atrelada à educação, o discurso da Participante 6, enquanto alguém que teve acesso ao ensino superior, é bastante enfático quando pontua que:

"Não é só a questão de empregabilidade, porque, automaticamente se aparece a vaga para a mulher trans, automaticamente vai solicitar que ela tenha conhecimento em relação a atribuição que ela vai desempenhar e ao mesmo tempo vai se questionar a questão da formação dela, então, se surge a vaga, automaticamente carece também de educação, e a gente sabe que hoje, um dos nossos maiores problemas para o público $T$, é justamente dar educação e da profissionalização e empregabilidade!"

Nota-se na fala da Participante 6 que o processo de inserção parte, antes de tudo, de uma qualificação, algo que agrega não apenas para o público trans em questão, mas para qualquer sujeito que busca uma colocação no mercado de trabalho formal: para tentar um processo seletivo, um currículo diferenciado faz toda diferença ao final do processo.

A valorização da educação enquanto elemento fundamental na busca por emprego ainda é pauta na fala da Participante 6, quando infere que:

"Porque eu acho que é algo em conjunto! Eu, graças

a Deus tive acesso à educação fundamental, ensino médio e logo após ao ensino superior, mas a gente sabe que não é uma realidade que são de todas, né? É uma realidade um pouco mais fragmentada e eu acho que a gente, na verdade, tem que pensar no outro para que possamos crescer juntos, juntas e juntes, né?" 
A fala da Participante 6 também pode ser relacionada à sua resposta na questão 18 do WHOQOL-Bref, relativa à satisfação em relação a sua capacidade de trabalho, em que ela pontuou sentir-se satisfeita, o que é avaliado no contexto geral de preocupação com o grupo com o qual se identifica, mesmo que a falta de capacitação não seja uma realidade dela.

Ao analisar os pressupostos expostos na fala e no questionário da Participante 6 , é necessário que se leve em consideração a sua história de vida, na qual todo esse processo educacional (ensino fundamental, médio e superior) foi vivenciado enquanto ela ainda era considerada como "ele", ou seja, antes da transição. Esta se deu a partir do fim das etapas educacionais da participante, que se acentuou na época em que trabalhava em um órgão de serviço público.

A travestifobia e a transfobia não se manifestam apenas em número de assassinatos todos os anos, mas essa discriminação está aliada a uma alta taxa de evasão escolar, baixo grau de instrução e à falta de representatividade no mercado de trabalho, sendo condenadas à invisibilidade social, vivendo à margem da sociedade, o que se manifesta de várias maneiras (Pedra et al., 2018).

Esse fragmento da importância da educação para o acesso ao trabalho é percebido na fala do Participante 4 e da Participante 5, enquanto uma dificuldade oriunda da falta de permanência nas escolas que as pessoas trans costumam vivenciar:

\section{"[...] existe muito preconceito e muitas pessoas não, não conseguem nem completar a escolaridade pra tentar entrar no mercado de trabalho." (Participante 4)}

O mesmo discurso acerca da evasão escolar foi encontrado na fala da Participante 5:

"[...] porque tem muita gente que abandona o estudo, sabe? E muita gente que não tem espaço em escola etc. Isso influencia bastante! Não é meu caso, porque eu tive acesso [...]."

Ao se analisar os discursos e comparar as respostas das/os referidas/os Participantes 4 e 5 ao questionário, na pergunta sobre o quão satisfeitas/os sentem-se com suas capacidades para o trabalho, o
Participante 4 apontou não estar satisfeito, porém tampouco se sente insatisfeito. Possibilitando assim, ser entendido como um sentimento de que não há desejo por mais qualificações, embora saiba que poderia tê-las; enquanto a Participante 5 respondeu estar muito satisfeita com suas capacidades, o que pode ser interpretado como um sentimento de prazer pelas capacidades que já tem. Embora as falas das/os participantes indiquem que se sentem insatisfeitos com suas habilidades profissionais, ainda apresentam a preocupação relativa à comunidade com a qual se identificam.

A educação deve ser vista como um direito de todos e a escola como um espaço público capaz de disponibilizar essa educação que não seja racista, sexista ou LGBTfóbica. Impedindo a reprodução de qualquer tipo de segregação discriminatória. As escolas são predominantemente marcadas por valores de concepções retrógradas e repletas de preconcepções e discriminações, o que favorece a reprodução de padrões heterossexistas e disseminação de conceitos da própria cis-heteronormatividade (Junqueira, 2015).

Quando ademais a educação não se torna eficiente como um instrumento de transformação social, acaba por si própria corroborando para a manutenção do status quo de preconceito e discriminação de grupos vistos enquanto minorias nas sociedades regidas por normas.

Diante disso, Foucault (1975/1999) discorre que a instituição de normas decorre, sobretudo, de um modelo de poder disciplinar. Ao se fazer necessário que se identifiquem as diferenças entre os sujeitos, passa a ser possível dar-Ihes a devida destinação, dominação e domesticação. Desta forma, aqueles indivíduos que porventura se desviam dela são destinados a procedimentos de correção, exclusão ou tratamento.

Os maiores efeitos dessa discriminação se configuram principalmente em: marginalização econômica, que corresponde à falta de acesso a trabalho remunerado ou a restrição à ocupação de cargos indesejáveis e mal remunerados; privação, que é a dificuldade para configuração de um padrão de vida adequado; e desrespeito, que compreende a persistência do estereótipo pejorativo e rotineiro de difamação e desqualificação de um grupo (Pedra, 2018). 
Portanto, nesse quesito fica exposto que a inserção de pessoas trans começa muito antes do que a não aceitação dos empregadores: ela vem da falta de capacitações, que não ficam disponíveis para esse grupo de pessoas marginalizadas.

\section{A influência dos papéis de gênero na busca pela qualidade de vida da população trans}

A Carta de Ottawa (1986), um dos principais documentos fundadores da promoção da saúde mundial, está associada a um conjunto de valores, tais como: qualidade de vida, saúde, solidariedade, equidade, democracia, cidadania, desenvolvimento, participação e parceria, entre outros. Assim, o conceito de qualidade de vida se refere às ações do Estado (políticas públicas), da comunidade (reforço da ação comunitária), de indivíduos (desenvolvimento de habilidades pessoais), do sistema de saúde (reorientação do sistema de saúde) e de parcerias intersetoriais.

A Participante 4 considerou frustrante o fato de não reconhecer pessoas trans ocupando cargos comuns. A invisibilidade é uma das consequências da pouca inserção de profissionais trans no mercado de trabaIho formal, reforçando o estigma:

"[...] é ainda mais complicado, a gente não vê, principalmente, travestis trabalhando à luz do dia, assim, é difícil a gente ver em qualquer tipo de trabalho, então, a gente tá aqui, e dá pra perceber que essas pessoas não estão contratando pessoas trans, em geral, sabe? [...]"

Esse fragmento da fala da participante sintetiza que, na observância da falta de postos de trabalho destinados para pessoas trans no geral, existe uma falta ainda maior para os sujeitos que se identificam enquanto travestis.

O subgrupo de travestis e mulheres transexuais brasileiras compõem um grupo específico de mulheres LGBT e, como tal, suas particularidades devem ser compreendidas. Nessa perspectiva, há um risco de serem inviabilizadas, levando em consideração o fato de que a expectativa de vida desta parcela da população é de apenas 35 anos, o que representa menos da metade da média nacional, que é de 75,5 anos, segundo dados do Instituto Brasileiro de Geografia e Estatística disponibilizados pela Agência Senado (Bortoni, 2017).
Nessa categoria discutiu-se também sobre a percepção com relação à qualidade de vida dessas pessoas, podendo-se objetificar o ponto central a partir da seguinte fala do Participante 4:

"[...] então eu só consigo ter uma saúde de qualidade, né, como coloquei no questionário, porque eu tenho ajuda da minha família, porque eu consegui me formar na faculdade.".

A questão do WHOQOL-Bref mencionada no discurso do Participante 4 levanta o ponto sobre o quão satisfeito ele está com sua saúde, o que é caracterizada em sua fala com um sentimento de razoabilidade, ou seja, ele pondera o fato de ter uma qualidade de vida, por receber um auxílio da família.

Em contrapartida, a resposta do Participante 1 aponta para uma percepção diferente em sua vivência:

"[...] ainda me martirizo muito por causa disso, por me ver... Me olhar no espelho e não me ver [...]".

Visando que a qualidade de vida anda junto ao bemestar pessoal, social e também de questões financeiras, pode-se observar a diferença, para construção de sua própria imagem, entre a/o participante que recebe apoio familiar e consegue se manter e aquela/e que ainda sente que não se vê como gostaria. Mediante o exposto, infere-se que a falta de possibilidade de realizar as mudanças necessárias no seu processo de passabilidade gerou implicações diretas na saúde e na autoestima do Participante 1.

Pode-se caracterizar a fala do Participante 1 ao apresentar sua resposta ao quesito do questionário sobre a satisfação com sua saúde, em que ele respondeu não estar satisfeito e nem insatisfeito, uma resposta que é entendida como se se tratasse de um ponto não interpretado por ele ou uma avaliação que não influencia em sua vida, seja positivamente ou negativamente.

Essa situação também surge na fala da Participante 2:

"[...] a partir do momento que eu falei, eu não sou isso, que comecei a transição... mesmo que clandestinamente, tomado remédios que, eu não consegui passar por um médico especialista, eu me sinto bem, só que eu não me sinto bonita, eu não me sinto... sabe... uma mulher ainda completa, porque, meus seios tão demorando crescer, porque eu não tô fazendo o tratamento direito, e é isso!". 
Em relação à avaliação da qualidade de vida, a Participante 2 avaliou como "Ruim" um ponto que é claramente entendido como a falta total de satisfação com o levantado; isso reforça o seu discurso sobre a insatisfação com as mudanças que deseja fazer em seu corpo, para se adequar a sua identidade. Essa questão não é correspondente à situação apresentada pelo Participante 4, quando questionado sobre como via a relação entre sua identidade de gênero e a qualidade de vida:

"Eu acho que... de uma forma geral afeta e no meu caso, por exemplo, que eu tomo hormônios, eu tenho que pagar endocrinologista, eu tenho que pagar os hormônios que aqui não tem, a gente não tem esse acesso aqui em Montes Claros, a ambulatório, né? Então isso passa dentro do meu orçamento, então com esse dinheiro eu poderia tá fazendo outras coisas, né? Se eu tivesse acesso a serviços públicos, então acredito que um acesso em grandes cidades acontece, mas que mesmo assim, não abrange todo mundo, né?".

É possível, ainda, observar as discordâncias dos discursos ao verificarmos a resposta do Participante 4 à questão de como avalia sua qualidade de vida, ligada à passabilidade, em que ele responde como "Boa", que pode ser entendida como razoável, embora pudesse ser melhor.

Analisando o conteúdo desses discursos, nota-se o impacto da relação de diferentes discriminações - a expressão da intersecção entre sistemas de opressão de classe e gênero, ou seja, diferentes identidades de gênero geram também diferentes oportunidades para promover a qualidade de vida mais aceitável ou não. Enquanto para a Participante 2 se apropriar da sua passabilidade (enquanto mulher trans) exigiu a utilização de meios clandestinos para tal finalidade, o Participante 4 já dispõe de um aparato médico, mesmo apresentando dificuldades de acesso.

Seguindo o mesmo ponto, pode-se citar também o discurso do Participante 3, que, ao responder à pergunta sobre a relação entre sua identidade de gênero e a qualidade de vida, concluiu que:

"Olha, eu vejo que no momento ela não está tão boa, mas logo em breve irá melhorar, e também o país nem colabora pra que a gente tenha uma qualidade de vida boa".
Na questão sobre avaliar sua qualidade de vida no questionário, o Participante 3, também a apontou como "Ruim", o que corrobora sua fala.

Os discursos evidenciam que as/os participantes têm diferentes visões sobre a qualidade de vida e entendem que, para se sentirem bem, necessitam das mais diversas influências, tanto subjetivas, quanto sociais e financeiras, o que aponta, inclusive, para uma "não qualidade de vida", como ressalta a Participante 6:

"Na verdade, eu não sei nem se a gente pode falar que a gente tem 'qualidade de vida' né? Porque é tudo muito complicado, geralmente a mulher trans, ela tem que sair da sua casa, justamente pelo fato de uma não aceitação da família; e a partir do momento que ela sai de casa, ela tem que se preocupar com a melhor forma de sobreviver. Na verdade, eu não falo nem que a gente vive, a gente sobrevive!"

A modo de comparação, é importante citar que, a respeito da mesma questão (sobre qualidade de vida), a Participante 6 marcou no questionário como "Boa", e um detalhamento dessa questão foi possível de ser observado em sua fala.

Os discursos de avaliação a respeito da qualidade de vida das pessoas trans devem ser avaliados a fundo, pesando-se a partir de todas as perspectivas que vão além do estar bem, visto que a sociedade cobra duas vezes mais delas/es e não Ihes dá nada de suporte. A partir dessas perspectivas, é possível apontar que os diversos pontos focais de suas vidas, que lhes conferem importância, parecem oscilar entre uma qualidade mínima e qualidade nenhuma, uma vez que o trabalho influencia na economia pessoal dos indivíduos e tal influência tem a capacidade de alterar a qualidade de vida.

A análise acerca da situação de travestis e transexuais no Brasil denota o maior número de assassinatos transfóbicos registrados no mundo, somados à alta mortalidade dessa população, que ainda arca com outros índices alarmantes, como a baixa escolaridade, a baixa inserção no mercado de trabalho e a alta taxa de evasão escolar (Pedra et al., 2018). 


\section{Considerações finais}

Este artigo pretendeu explorar a percepção acerca das influências dos papéis de gênero sobre as pessoas transexuais na inserção no mercado de trabalho. Este estudo foi capaz de coletar dados significativos, que podem servir de reflexão e compor um arcabouço científico na Psicologia e em outros espaços, nos assuntos sobre os temas relacionados à questão de gênero, mercado de trabalho e qualidade de vida.

O estudo também possibilitou dimensionar a importância de pesquisas científicas voltadas para a população LGBTQIA+, uma vez que derivam de ricas contribuições acerca dessa identidade grupal, que coexiste em uma sociedade cis-heteronormativa, ao passo que sistematicamente precariza essas vivências, aumentando consideravelmente a vulnerabilidade social, a exclusão e a falta de políticas públicas eficazes voltadas para essa parcela da população.

Esta pesquisa apresentou limitações, entre elas a dificuldade relativa à identificação de participantes e a dificuldade de acesso à internet daquelas/es que aceitaram fazer parte desse trabalho - embora tenha-se conseguido entrar em contato com a maioria, houve aqueles que não tinham acesso à internet ou não se sentiam bem ao serem contatadas/os através desses meios de comunicação, ou mesmo de concederem a entrevista através de plataformas digitais.

A pesquisa também demonstrou que, para o alcance de uma qualidade de vida satisfatória, é necessário que vários pontos sejam alcançados, como: a educação, o trabalho, a segurança pessoal e a capacidade de relacionamento interpessoal. Seguindo esse pensamento, vale ressaltar o ponto levantado neste estudo, em que se discutiu sobre a necessidade de capacitação para a população trans. São necessárias políticas públicas específicas para esse grupo de pessoas, a fim de que sejam bem-recebidos e acolhidos nos espaços de ensino, e que também recebam apoio, quando buscarem por trabalho, para que não sejam discriminadas/os pelas suas identidades, algo que é tão importante na construção de suas vidas.
A efetivação desse trabalho deu luz à latente questão sobre a marginalização de pessoas trans e a exclusão social a que estão expostas, fazendo com que direitos universais da população não consigam ser acessados. Defende-se que essa discussão seja levantada não somente em âmbito acadêmico, mas, também, para os espaços além-muros, a fim de se atender a essas necessidades, e que se possam produzir mudanças significativas contra a cultura do preconceito e da rejeição.

Por fim, considera-se que é dever da academia produzir conhecimento científico que seja voltado para a comunidade, com a finalidade de contribuir para a discussão, reflexão e mobilização dos grupos, tornando esses estudos uma base para a implementação de ações afirmativas eficazes que contemplem essa população e promovam a mudança social necessária.

\section{Agradecimentos}

Aos nossos familiares por toda paciência e apoio durante a jornada desta pesquisa. A Worney Ferreira de Brito, por toda dedicação em suas orientações, pelas correções, pela paciência e pelos ensinamentos que permitiram o melhor desempenho no processo de construção e realização deste trabalho. $E$ a todos aqueles que contribuíram, direta ou indiretamente, para a existência deste artigo, e que sempre apoiam novas pesquisas com foco na luta de direitos pela população LGBTQIA+.

\section{Contribuições dos autores}

Ferreira FF participou da concepção, coleta dos dados da pesquisa, interpretação dos resultados e redação do artigo científico. Ribeiro TMS participou do delineamento, análise dos dados da pesquisa, interpretação dos resultados e redação do artigo científico. Brito WF participou da concepção, delineamento e orientação da pesquisa e construção do artigo científico.

\section{Conflitos de interesses}

Nenhum conflito financeiro, legal ou político envolvendo terceiros (governo, empresas e fundações privadas etc.) foi declarado para nenhum aspecto do trabalho submetido (incluindo, mas não se limitando a subvenções e financiamentos, participação em conselho consultivo, desenho de estudo, preparação de manuscrito, análise estatística etc.). 


\section{Referências}

Adelman, M., Ajaime, E., Lopes, S. B., \& Savrasoff, T. (2003). Travestis e transexuais e os outros: identidade e experiências de vida. UFF, 4(1), 119-41. https://periodicos. uff.br/revistagenero/article/view/31023/0

Associação Brasileira de Lésbicas, Gays, Bissexuais, Travestis e Transexuais. (2010). Manual de comunicação LGBT. https://www.academia.edu/6273564/Manual de Comunica\%C3\%A7\%C3\%A30_LGBT

Bortoni, L. (2017). Expectativa de vida de transexuais é de 35 anos, metade da média nacional. Senado Federal. https:// www12.senado.leg.br/noticias/especiais/especialcidadania/expectativa-de-vida-de-transexuais-e-de-35anos-metade-da-media-nacional/expectativa-de-vida-detransexuais-e-de-35-anos-metade-da-media-nacional

Butler, J. (2003). Problemas de gênero: feminismo e subversão da identidade. Civilização Brasileira. (Trabalho originalmente publicado em 1990)

Caregnato, R. C. A., \& Mutti, R. (2006). Pesquisa qualitativa: análise de discurso versus análise de conteúdo. Texto \& ContextoEnfermagem, 15(4), 679-84. https://doi.org/10.1590/S010407072006000400017

Carpilovsky, A. (2020, 04 de fevereiro). Passabilidade: a aparência também como barreira para trans no trabalho. Projeto Colabora. https://projetocolabora.com.br/ods5/ passabilidade-a-aparencia-tambem-como-barreira-paratrans-no-mercado-trabalho

Cayres, R. M. V., Silva, L. C., \& Silva, D. I. (2020). Cocriação para a dignidade e empregabilidade das mulheres transexuais: a experiência do projeto Transcuidadorxs. Periódico Eletrônico Fórum Ambiental da Alta Paulista, 16(2). https:// doi.org/10.17271/1980082716220202328

Cruz, L. E. M. P., Barreto, M. L. S., \& Dazzani, M. V. M. (2020). Do gênero aos papéis sociais: a construção da identidade da pessoa transexual. Interfaces CientíficasEducação, 8(2), 299-314. https://doi.org/10.17564/23163828.2020v8n2p299-314

Fleck, M., Louzada, S., Xavier, M., Chachamovich, E., Vieira, G., Santos, L., \& Pinzon, V. (2000). Aplicação da versão em português do instrumento abreviado de avaliação da qualidade de vida" WHOQOL-bref". Revista de saúde pública, 34(2), 178-83. https://doi.org/10.1590/\$0034$\underline{89102000000200012}$
Foucault, M. (1984). História da sexualidade II, o uso dos prazeres. Graal.

Foucault, M. (1999). Vigiar e punir: nascimento da prisão. Vozes. (Trabalho originalmente publicado em 1975)

Gomes, F. S. (2007). Discursos contemporâneos sobre Montes Claros: (re)estruturação urbana e novas articulações urbanoregionais [Dissertação de mestrado, Universidade Federal de Minas Gerais]. Repositório Institucional da UFMG. https://repositorio.ufmg.br/handle/1843/RAAO-7BMQ8A

Jesus, J. G. (2012). Orientações sobre identidade de gênero: conceitos e termos. Guia técnico sobre pessoas transexuais, travestis e demais transgêneros, para formadores de opinião (2a. ed.). http://www.diversidadesexual.com.br/wpcontent/uploads/2013/04/G\%C3\%8ANERO-CONCEITOS-ETERMOS.pdf

Junqueira, R. D. (2015). A Pedagogia do Armário: heterossexismo e vigilância de gênero no cotidiano escolar. Revista Educação On-line PUC, 10, 64-83. https://www. maxwell.vrac.puc-rio. $\mathrm{br} / 20040 / 20040 . P D F$

Kaffer, K. K., Ramos, F. G., Alves, A. L., \& Tonon, L. (2016). A transexualidade e o mercado formal de trabalho: principais dificuldades para a inserção profissional. In Anais do Congresso Brasileiro de Estudos Organizacionais. https://anaiscbeo.emnuvens.com.br/cbeo/article/view/52

Maria, V. A. (2020). A realidade e os desafios para a inserção de transgêneros, transexuais e travestis no mercado de trabalho a realidade e os desafios para a inserção de transgêneros, transexuais e travestis no mercado de trabalho. Revista Conteúdo Jurídico. https://www. conteudojuridico.com.br/consulta/Monografias-TCCTeses/54865/a-realidade-e-os-desafios-para-a-inserode-transgneros-transexuais-e-travestis-no-mercado-detrabalho

Ministério da Saúde. (1986). Primeira Conferência Internacional sobre promoção da saúde. https://bvsms.saude.gov.br/bvs/ publicacoes/carta ottawa.pdf

Organização das Nações Unidas para a Educação, a Ciência e a Cultura. (1948). Declaração universal dos direitos humanos. https://ead.stf.jus.br/cursos/controleconstitucionalidade/ files/aula3/declaracao_universal_direitos_humanos.pdf

Pedra, C. B., Souza, E. C., Rodrigues, R. V. A., \& Silva, T. S. A. (2018). Políticas Públicas para Inserção Social de Travestis e Transexuais: Uma Análise do Programa "Transcidadania". Revista de Ciências do Estado, 3(1). https://doi. org/10.35699/2525-8036.2018.5091 
Reis, A. F. (2019). O processo de construção da identidade de gênero e transexualidade: narrativas, trânsitos e diferenças. Interfaces da educação, 10(28), 93-116. https:// doi.org/10.26514/inter.v10i28.2960

Schmidt, B., Palazzi, A., \& Piccinini, C. A. (2020). Entrevistas online: potencialidades e desafios para coleta de dados no contexto da pandemia de covid-19. Revista Família, Ciclos de Vida e Saúde no Contexto Social, 8(4), 960-66. https://doi. org/10.18554/refacs.v8i4.4877

Silva, G. (2020, 06 de outubro). Qual o significado da sigla LGBTQIA+?. https://www.educamaisbrasil.com.br/ educacao/dicas/qual-o-significado-da-sigla-Igbtqia
Silva, R. G. L. B., Bezerra, W. C., \& Queiroz, S. B. (2015). Os impactos das identidades transgênero na sociabilidade de travestis e mulheres transexuais. Revista de Terapia Ocupacional da Universidade de São Paulo, 26(3), 364-72. https://doi.org/10.11606/issn.2238-6149.v26i3p364-372

Sousa, V., \& Arcoverde, L. (2019, 17 de maio). Brasil registra uma morte por homofobia a cada 23 horas, aponta entidade LGBT. https://g1.globo.com/sp/sao-paulo/ noticia/2019/05/17/brasil-registra-uma-morte-porhomofobia-a-cada-23-horas-aponta-entidade-lgbt.ghtml 